\title{
Revista

\section{PROGRAMAS DE REDISTRIBUIÇÃO DE RENDA: AS PROPOSTAS DOS 13 PRESIDENCIÁVEIS NAS ELEIÇÕES BRASILEIRAS DE 2018}

\section{INCOME REDISTRIBUTION PROGRAMS: THE PROPOSALS OF THE 13 PRESIDENTIAL IN THE BRAZILIAN ELECTIONS OF 2018}

\author{
Nome \\ Thaesa Jesana da Silva Bacellar \\ Instituição/Afiliação \\ Universidade Federal de Santa Maria \\ País \\ Brasil \\ Nome \\ Tiago Guterres de Freitas \\ Instituição/Afiliação \\ Universidade Federal de Santa Maria \\ País \\ Brasil \\ Nome \\ Nelson Guilherme Machado Pinto \\ Instituição/Afiliação \\ Universidade Federal de Santa Maria \\ País \\ Brasil
}

\section{RESUMO}

Esse artigo trata da análise dos Planos de Governo dos presidenciáveis na eleição de 2018 no Brasil. O tema foi escolhido tendo em vista a relevância dos programas de transferências e redistribuição de renda para a superação da miséria e da pobreza no país, conforme demonstra a literatura. Para desenvolvimento do estudo de caso foi realizado um levantamento bibliográfico e uma análise documental dos referidos planos disponibilizados no site do Tribunal Superior Eleitoral, através da metodologia de análise de conteúdo. Foi possível concluir que os planos de governo são uma importante ferramenta para que a sociedade tome ciência dos projetos que irão compor agenda de governo dos candidatos. A presença da temática dos programas de redistribuição de renda nos planos dos presidenciáveis auxilia na identificação da relevância atribuída ao tema nas plataformas de governo o que poderá vir a impactar na vida dos segmentos mais vulneráveis da população.

Palavras-Chave: Planos de Governo; Eleições Presidenciáveis 2018; Programas de Redistribuição de Renda. 


\title{
Revista \\ UNEMAT de Contabilidade
}

\begin{abstract}
This article deals with the analysis of the Plans of Government of the presidential candidates in the 2018 election in Brazil. The theme was chosen in view of the relevance of transfer programs and income redistribution in order to overcome poverty and poverty in the country, as shown in the literature. For the development of the case study, a bibliographical survey and a documentary analysis of the said plans were made available on the website of the Superior Electoral Court, through the methodology of content analysis. It was possible to conclude that government plans are an important tool for society to become aware of the projects that will make up the candidates' government agenda. The presence of the issue of income redistribution programs in the presidential plans assists in identifying the relevance attributed to the theme in the government platforms, which may impact on the life of the most vulnerable segments of the population.
\end{abstract}

Keywords: Government Plans; Presidential Elections 2018; Redistribution of Income Programs.

\section{INTRODUÇÃO}

Após 20 anos de Ditadura Militar, teve início nos meados dos anos 70 o período de redemocratização brasileira que culminou com as eleições indiretas de Tancredo Neves, do Partido do Movimento Democrático Brasileiro (PMDB), sendo que o presidente eleito faleceu antes de assumir o poder. Seu vice, também do PMDB, José Sarney assumiu o cargo. Teve início o período conhecido como Nova República, que perdura até os dias atuais. (KINZO, 2001).

Em 1988, ocorreu a promulgação da nova Constituição Federal, garantindo a execução de eleições diretas. Após a eleição, em 1989, assume o poder Fernando Collor de Mello, do Partido da Reconstrução Nacional (PRN). Fernando Collor não completou seu mandato, renunciando em dezembro de 1992, pouco antes de ser condenado pelo Senado por crime de responsabilidade. Assumiu seu vice, Itamar Franco, do PMDB, para um mandato 'tampão' que durou até $1^{\circ}$ de janeiro de 1995 (JACOB et al, 2000).

No que se refere a esfera política, esse período foi de avanço democrático, culminando na campanha das "Diretas Já". Essa mobilização popular evidenciou a organização da sociedade civil influindo diretamente nos rumos democráticos do país. Porém, o processo de eleições diretas só foi ocorrer no Brasil no ano de 1987, após quatro anos do início das mobilizações. Cabe destacar que a efervescência do ambiente democrático possibilitou a construção da Constituição de 1988, que apesar de manter alguns privilégios da classe política representou uma importante conquista no que se refere a responsabilização do Estado quanto a proteção social dos indivíduos (KINZO, 2001).

Atualmente, desde a publicação da Constituição Federal 1988, vivenciou-se o oitavo período eleitoral com eleições diretas para escolha de um novo presidente para o Brasil. No período eleitorial, os presidenciáveis apresentam e defendem os seus planos de governo. Esses programas de governo são elaborados em uma conjuntura específica e para um determinado período refletindo o posicionamento do partido e/ou da coalizão eleitoral que apoia o candidato (MADEIRA, et al., 2017).

O período eleitoral é o período em que os candidatos e seus partidos políticos ou coligações, após terem seus registros de candidaturas aprovadas pelo Tribunal Superior Eleitoral 


\section{Revista \\ UNEMAT de Contabilidade}

(TSE), apresentam suas propostas de governo para os cidadãos a fim de angariar votos e firmar seu papel na construção da agenda política do país. Portanto, esse período é crucial no que concerne a reafirmação da democracia do Brasil bem como possibilita que os partidos políticos deem visibilidade as suas estratégias e concepções econômicas, sociais e políticas, que influem na esfera pública (BARROS, 2015). Diante desse contexto, é provocado um debate entre os cidadãos dos rumos da nação e das prioridades almejadas para o Estado.

Todo candidato à presidência precisa ter uma proposta de programa de governo. Segundo art. $11, \S 1^{\circ}$, IX, da Lei 9.504/97, o pedido de registro de candidatos à Chefia do Executivo deve conter, entre outros documentos, as propostas defendidas pelo candidato. Uma via impressa e outra digitalizada da plataforma ou plano de governo deve ser entregue à Justiça Eleitoral. Essa exigência permite que os cidadãos conheçam os planos de governo dos candidatos desde o mês de agosto, já que os partidos e coligações devem solicitar à Justiça Eleitoral o registro de seus candidatos até às dezenove horas do dia 15 de agosto do ano em que se realizarem as eleições (BRASIL, 1997).

As plataformas de governo apresentam os compromissos, as metas e os objetivos de trabalho que os candidatos pretendem desenvolver nas diferentes áreas de governo, como no setor econômico, na saúde, na educação, infraestrutura, meio ambiente e na área social. Assim, as eleições são de grande importância para as políticas públicas, pois, o resultado do processo eleitoral incide nas possibilidades de reformulação das ações do Estado (FERLA, et al., 2017).

Nesse sentido pretende-se identificar como os candidatos à presidência da república do Brasil, nas eleições de 2018, apresentam os programas sociais com ênfase na redistribuição de renda em seus planos de governo. $\mathrm{O}$ debate referente a transferência de renda ganhou visibilidade a partir do ano de 1991, quando o Senador Eduardo Suplicy pelo projeto de lei $\mathrm{n}^{\circ} 80$, propôs a instauração de um Programa de Renda Mínima a partir do estabelecimento de critérios de inclusão (SUPLICY, 2002). Assim, na década de 1990 deu-se início a alguns programas de transferência de renda, tendo dentre os marcos históricos o Programa Bolsa Escola de 1995.

Os programas de transferência ou redistribuição de renda fazem parte do sistema de proteção social brasileiro, tendo por conceito conforme afirmam Silva et al. (2004, p. 48) a "transferência monetária à família ou indivíduos, transferência esta, na maioria dos programas, associada as exigências de contrapartida no campo da educação, da saúde e do trabalho". Atuam assim na desigualdade social, considerando que a riqueza socialmente produzida é individualmente apropriada. Exige, entretanto, a focalização, no que se refere a quem financia essa política e quem dela pode ser beneficiado.

Portanto, os programas de transferência ou redistribuição de renda são importantíssimos para o país, sendo uma das respostas estatais mais efetivas no combate à pobreza e a erradicação da extrema miséria. Porém, não devem ser descolados de outras ações estatais e políticas públicas a fim de que para além do combate à miséria no Brasil, possam representar uma melhoria real nas condições de vida da população (MARINHO et. al. 2011; ARAUJO, FLORES, 2017).

Assim, o presente trabalho irá se orientar pelo seguinte problema de pesquisa: Como os presidenciáveis, nas eleições de 2018, apresentam em seus planos de governo os programas de redistribuição de renda? Em função do problema apresentado foram definidos os seguintes objetivos de pesquisa: discutir a relevância dos programas de redistribuição de renda no Brasil e os impactos na melhoria das condições de vida da população; analisar o plano de governo dos 13 


\section{Revista \\ UNEMAT de \\ Contabilidade}

candidatos à presidência da república do Brasil e fazer comparativo no que concerne aos programas sociais, com ênfase nos programas de redistribuição de renda.

A principal justificativa pela qual se escolheu o tema é a importância de se conhecer e debater as propostas dos presidenciais no que diz respeito às políticas de redistribuição de renda no país contribuindo assim para a conscientização e para a crítica por parte dos eleitores no que diz respeito à diminuição das desigualdades sociais. Cabe destacar que não há nenhum mecanismo legal de sanção ao candidato que após eleito não cumpra suas propostas, evidenciando a importância do controle social por parte da população que só será possível mediante o debate a publicização dos planos de governo.

O processo metodológico foi baseado na análise de conteúdo dos programas de governo, com o propósito de mapear como os presidenciáveis apresentam em seus planos de governo os programas de redistribuição de renda. O levantamento foi realizado no período de setembro a outubro de 2018, durante a campanha eleitoral. Antes da análise dos dados, foi traçada uma breve contextualização sobre a inserção das políticas sociais na governança política no mundo e no Brasil.

Para atingir seus objetivos, este artigo foi dividido em cinco seções, começando por esta parte introdutória, na seção seguinte, é colocado o referencial teórico, na terceira parte descrevese o método utilizado para realização desta pesquisa e na quarta seção expõem-se os resultados e discussão. Na quinta etapa têm-se as considerações finais do estudo e por fim relacionam-se as referências que foram utilizadas.

\section{FUNDAMENTAÇÃO TEÓRICA}

\section{sociais \\ 2.1. Qual o papel central do Estado? Uma breve constituição histórica das políticas}

Após o período medieval a sociedade passa a questionar o papel do Estado. Esse debate ganha força desde os conhecidos filósofos contratualistas, a exemplo de Hobbes em Leviathan (1651) onde aborda o poder destrutivo dos desejos e paixões dos seres humanos e que nesse sentido, o Estado atuaria como um mediador e protetor na medida em que as pessoas sujeitas aquele estado abrissem mão de sua liberdade individual. Essa concepção de Estado permaneceu em discussão e foi reacendida pelo pensamento de Keynes (BEHRING, BOSCHETTI, 2007).

A recessão econômica ocorrida na Grande Depressão de 1929 evidencia que alguns pressupostos da economia política não explicavam todos os acontecimentos. A lei de Say ou lei dos mercados foi questionada por Keynes ao constatar o desequilíbrio econômico da auto regulação do mercado. Keynes fundamenta o ideário do Estado de Bem Estar Social, tendo por princípio o Pleno Emprego e a diminuição da desigualdade social entre os cidadãos. Tem por concepção de Estado que este tem a responsabilidade pela garantia de um padrão mínimo de qualidade de vida aos cidadãos. Para tanto o Estado deverá intervir na economia, criando serviços sociais de interesse coletivo, como educação, saúde e assistência social, entendendo essas políticas enquanto viabilizadoras de direitos dos cidadãos (PIANA, 2009).

Cabe ressaltar que não é possível estimar o período específico do surgimento das primeiras políticas sociais, pois, é parte de um processo social, emergindo da confluência do desenvolvimento do estado e das demandas oriundas da industrialização (PIANA, 2009). No 


\section{Revista \\ UNEMAT de Contabilidade}

Brasil nunca houve plenamente o Estado de Bem Estar Social por meio da universalização de direitos e serviços estatais devido à profunda desigualdade entre as classes. Nesse contexto as políticas sociais tomaram um carácter focalizado em determinadas categorias de público alvo da população (FALEIROS, 1991).

Dentro desse contexto as políticas sociais tiveram um fortalecimento no período keynisiano. Cabe ressaltar, no entanto, que houve movimentos operários antes e depois desse período preponderante para a conquista de alguns mecanismos de proteção social, principalmente no que concerne as inseguranças da vida do trabalhador, como o desemprego, a velhice e a doença. Foram criadas Caixas de Aposentadoria e Pensão, que deu início a seguridade social. Assim, o Estado enquanto gestor de ações anti-crise, implementa sistemas nacionais de seguridade, utilizando essas poupanças obrigatórias dos trabalhadores como fundo de empréstimo além do atendimento a uma demanda da população (BEHRING, BOSCHETTI, 2007).

A década de 1970 foi marcada pelo declínio do modelo de bem-estar em razão dos altos índices inflacionários. As garantias ofertadas pelo Estado a população passaram a ser percebidas como entraves ao desenvolvimento do capital (PIANA, 2009). Há, assim, novo fôlego a teoria do liberalismo, ou neoliberalismo, tendo por princípio o Estado como responsável pela estabilidade monetária, mas, pouco interventivo no que se refere às políticas sociais (BEHRING, BOSCHETTI, 2007).

Um importante marco legal na história da política social do Brasil foi a Constituição Federal brasileira (1988) a qual estabelece a Seguridade Social e responsabiliza o Estado como principal gestor das políticas sociais. Reafirma assim os direitos da população atribuindo as políticas sociais a função de promover e garantir os direitos, bem como de prevenir a sua violação. Porém, como ressalta Yasbek (2004) se por um lado a Constituição de 1988 consolida a Seguridade Social e os direitos dos cidadãos, o quadro social do período caracterizou-se por uma retração dos investimentos públicos no campo social e pelo reordenamento das políticas sociais as demandas de mercado e sua perspectiva privatizadora.

Portanto, a política social, é interligada aos fatores econômicos, políticos e sociais movimentando-se conjuntamente em seus processos de mudança (BEHRING, BOSCHETTI, 2007). Segundo Paina (2009) as políticas sociais têm uma função econômica no que se refere a ação do Estado por meio da transferência direta ou indireta de bens e recursos aos usuários mais vulneráveis da população ou através da prestação de serviços sociais. Essas ações são compensatórias a queda do salário real ou ao não suprimento através do salário dos direitos básicos dos cidadãos.

Dessa forma, as políticas sociais são estratégias governamentais de fortalecimento da mão-de-obra ou força de trabalho, mas mais do isso, pertencem a um emaranhado complexo de atores sociais com diferentes interesses. Para além da manutenção de trabalhadores para o mercado de trabalho a política social é um instrumento de proteção e garantia de direitos a população (PIANA, 2009). Nesse sentido o Estado, é uma arena de disputas de múltiplas concepções e determinações que incidem diretamente sobre os rumos das políticas sociais. 


\section{Revista \\ UNEMAT de \\ Contabilidade}

\subsection{Programas de Transferência de Renda no Brasil e os impactos na melhoria das condições de vida da população}

A Constituição brasileira de 1988 teve como um de seus grandes avanços a instituição de um sistema de Seguridade Social, positivando a obrigação legal do Estado para com a população. Rompe-se com a concepção do favor, da caridade, reafirmando que todos independente de encontrarem-se ou não em uma situação de vulnerabilidade, tenham sua dignidade respeitada e o reconhecimento enquanto cidadãos. É nesse contexto que surgem as primeiras iniciativas dos Programas de Transferência de renda no Brasil (SILVA, 2007).

Em 1991 foi apresentado e aprovado no Senado Federal brasileiro o projeto de Lei n. 80/1991 do senador Eduardo Suplicy. O projeto instituiu o Programa de Garantia de Renda Mínima, que tinha por objetivo beneficiar os brasileiros com mais de 25 anos e com renda de até 2,5 salários mínimos. A partir desse marco o debate sobre os programas dessa natureza passam a se sustentar por dois argumentos principais: o primeiro é o custo oportunidade para as famílias manterem seus filhos na escola e o segundo refere-se à deficiência da formação educacional como fator limitante para elevação de renda das futuras gerações. Assim, a família passou a ser considerada como unidade beneficiária, articulando-se uma compensação monetária pela transferência de renda a uma política estruturante como a educação (SILVA, 2007).

Outras iniciativas deram sequência aos programas de transferência de renda, como o Benefício de Prestação Continuada, positivado na Constituição Federal e regulamentado pela Lei Orgânica de Assistência Social em 1993 e implementado em 1996, assim como, o Programa de Erradicação do Trabalho Infantil e o Programa Bolsa Escola (YASBEK, 2004).

Em outubro de 2001 foi apresentada uma proposta pública elaborada pelo Instituto de Cidadania, com a participação da sociedade civil organizada (ONGs, institutos de pesquisa, sindicatos, organizações populares, movimentos sociais e especialistas) referente à segurança alimentar no país. Partindo do princípio de que a alimentação é um direito e deve ser garantido pelo Estado, formulou-se a Política de Segurança Alimentar e Nutricional. Esse documento marcou a preocupação com a conjugação adequada entre as políticas estruturais voltadas a redistribuição de renda, crescimento da produção, geração de emprego, reforma agrária entre outros. No entanto, afirma que o combate à fome não poderia esperar a conquista prévia dessas mudanças profundas nas políticas estruturais, mas, sua operacionalização poderia contribuir para que essas mudanças ocorram (YASBEK, 2004).

Assim, esse documento contribui no reconhecimento que no Brasil a pobreza e o desemprego são as principais causas da fome e que o enfrentamento desse cenário deve ser realizado obrigatoriamente em articulação com a sociedade civil (Projeto Fome Zero, 2002). Cabe ressaltar que na história do Brasil nunca houve um programa global voltado ao enfrentamento da pobreza, indo além de medidas focalizadas, seletivas e compensatórias. Nesse cenário o Programa Fome Zero não apresenta novidades, pois unifica iniciativas já existentes, mas, sua principal contribuição diz respeito à inclusão na agenda governamental do enfrentamento a pobreza, alinhando a segurança alimentar a estratégias permanentes de desenvolvimento econômico e social (YASBEK, 2004).

Em outubro de 2003, sob a justificativa de enfrentar os ainda permanentes, altos índices de desigualdade social, bem como ampliar os recursos para os Programas de Transferência de Renda, foi lançado o Programa Bolsa Família (PBF). O PBF unificou inicialmente os programas 


\section{Revista \\ UNEMAT de Contabilidade}

Bolsa Escola, Bolsa Alimentação, Cartão Alimentação e Vale Gás e posteriormente também integrou o Programa de Erradicação do Trabalho Infantil. Essa unificação passou a exigir que os estados e municípios, além da união, sejam corresponsáveis pela implementação do PBF. O programa também demandou o fortalecimento dos espaços de controle social, tendo exigência e existência e pleno funcionamento de um conselho de direitos ou um comitê local (SILVA, 2007). A parceria dos municípios com a união para adesão ao programa foi normatizada pela Portaria GM/MDS no 246/05 (BRASIL, 2005).

O PBF é o principal Programa de Transferência de Renda da união. Objetiva o combate à fome, pobreza e desigualdade por meio de um benefício monetário e associado a garantia de acesso aos direitos referentes a saúde, educação, assistência social e segurança alimentar. Essa ligação com as políticas estruturantes se dá, entre outras medidas, pelas condicionalidades que a família deve cumprir como uma forma de contrapartida ao recebimento do valor financeiro. $\mathrm{O}$ público alvo do PBF é a família, composta por laços de afinidade ou parentesco, que compartilham o mesmo ambiente doméstico, isto é, a mesma residência. Objetiva a proteção social de famílias na linha da miséria com renda, por pessoa, de até $\mathrm{R} \$ 60,00$ e até $\mathrm{R} \$ 120$ para famílias compostas por gestantes, crianças e adolescentes de até quinze anos. O programa tem ampliado seu público alvo para pessoas em situação de rua, quilombolas e indígenas (SILVA, 2007).

O PBF assumiu uma dimensão política, econômica e simbólica ao conseguir mobilizar diversos atores sociais e formadores de opinião. Deu visibilidade a questão da pobreza, em seu caráter amplo e multidimensional, no Brasil, desvelando a existência de grande contingente populacional de famílias em extrema pobreza. Demonstrou também, que as políticas sociais, não estavam suprindo à demanda da proteção social a população, requerendo uma atuação inter setorial. Com o PBF o país avançou em direção a inclusão social e no estabelecimento de padrões de bem-estar mínimos para a população, o que os países europeus já desenvolveram em um Estado de Bem Estar Social (VAITSEMAN et.al., 2009).

O impacto dos Programas de Transferência de Renda é modesto para superação da pobreza no Brasil, no entanto, são um importante mecanismo de enfrentamento por parte do governo da desigualdade social (YASBEK, 2004; SOARES et. al, 2006). Sem os programas de transferência direta de renda dificilmente se avançaria na erradicação da miséria. Não podem, no entanto, constituir uma solução única e permanente para os problemas sociais do país (SOARES et. al, 2006). Yasbek (2004) coloca a inegável importância dos programas de transferência de renda, porém, afirma que esses programas não conseguem ir além da manutenção de um certo nível de pobreza.

Segundo o Word Bank (2014) o PBF é o "programa mais bem-sucedido de todos os tempos". Segundo os dados da instituição, o PBF conseguiu reduzir pela metade a miséria no Brasil (de 9,7\% para 4,3\%). Ainda segundo o Word Bank (2014) 1,7 milhões de beneficiários deixaram voluntariamente o programa, diante da melhoria na qualidade de vida e acesso a renda, tornando-se uma referência mundial, sendo que até 2013, 120 delegações visitaram o país para conhecer o programa. Destaca, porém, o desafio presente do Estado brasileiro oferecer oportunidades de trabalho e serviços para o povo.

Portanto, os programas de transferência de renda são essenciais para a diminuição da desigualdade social e garantia dos direitos da população (SOARES et. al, 2006). Tem por potencialidade a criação de condições progressivas e de longo prazo para a inclusão social de 


\section{Revista \\ UNEMAT de \\ Contabilidade}

futuras gerações a partir do acesso as políticas de educação, assistência social e saúde (YASBEK, 2004).

Porém, o sucesso dessas ações depende de uma mudança significativa nas políticas sociais, pois, somente a partir de um trabalho integrado entre essas será possível ofertar uma maior proteção social a população bem como uma melhoria real em sua qualidade de vida. Por conseguinte, os Programas de Transferência de Renda são um passo imprescindível no combate à fome e a miséria no país, o que evidencia a relevância de sua manutenção e continuidade na agenda governamental.

\subsection{Participação social: explorando o conteúdo dos planos de governo}

Busca-se que a participação dos cidadãos no processo eleitoral não seja resumida ao simples ato de comparecer às urnas. O ideal é que sua atuação se inicie no período pré-eleitoral e que seja expandida para toda a temporada que o governante eleito permanecer em seu cargo desenvolvendo as políticas públicas priorizadas pela sua política de governo. Em relação a isso Barros e Elliot (2018, p. 198) ressaltam que "As políticas públicas no Brasil são formuladas para atingir metas de atuação do governo no sentido de implementar ações governamentais necessárias à gestão do Estado, em nível federal, estadual e municipal." Dessa maneira, percebe-se a relevância de se conhecer as promessas e metas postas pelo governo, bem como realizar o acompanhamento da concretização do seu programa de governo.

À vista disso, entende-se que os cidadãos devem ter uma atuação ativa nas eleições, bem como na construção do novo governo, atuando desde o período eleitoral até a formação e fiscalização das políticas públicas desenvolvidas pelo governo. Nessa lógica Milani (2008) acena que a participação social na gestão das políticas públicas, que se traduz na inclusão dos cidadãos e das organizações da sociedade civil no processo decisório, possibilita a criação de uma rede que pode informar, elaborar, implementar e avaliar as decisões políticas.

Adotando essa postura participativa, desponta o papel do cidadão-eleitor que em um primeiro momento ao inteirar-se da formação da agenda dos postulantes ao Palácio do Planalto poderá contribuir para a formação de um governo mais democrático e participativo e, em um segundo momento, será capaz de atuar propondo e fiscalizando as políticas públicas que serão implementadas pelo futuro representante do povo. Nesse cenário, para conhecer os compromissos firmados frente aos eleitores, os planos de governo dos candidatos à Presidência, que são entregues ao Tribunal Superior Eleitoral (TSE), por exigência legal até a data anterior ao início da campanha eleitoral, colocam-se como importantes ferramentas para que os cidadãos, desde já, tenham um primeiro contato com as propostas dos presidenciáveis para as diferentes áreas de atuação do Estado.

Como vive-se em um grupo social no qual as questões políticas afetam a todos e em um sistema político democrático no qual as decisões devem ser tomadas com liberdade, participação e respeitando a vontade coletiva a participação na vida política, é fundamental para construção de uma sociedade mais comprometida com as questões sociais (DALLARI, 2010). Nesse sentido, participar do processo eleitoral, desde o período eleitoral até avaliação das decisões tomadas pelos governantes, permite influenciar na definição das políticas públicas que serão prioritárias no país nos próximos anos, bem como avaliar o seu impacto na vida da população, influenciando assim na vida de todos. 


\section{Revista \\ UNEMAT de Contabilidade}

Por esse motivo é que quanto mais efetiva a participação social no processo eleitoral, tomando conhecimento do conteúdo dos programas de governo e comparando as propostas dos candidatos, maiores serão as chances de escolher nas urnas aquele candidato que melhor atenda aos anseios da sociedade e que poderá desenvolver um programa que atenda as demandas da coletividade. Isso posto, acena que conhecer as propostas dos presidenciáveis é essencial para fazer uma projeção de como poderá vir a ser a agenda governamental para as diferentes políticas públicas. Nesse sentido, Madeira et. al. (2017) afirma que os programas de governo constituem um rico instrumental analítico para se conhecerem as prioridades dos atores políticos. Assim, considerando importância dos programas de transferências de renda no luta contra a desigualdade social no Brasil, será mapeado a seguir, entre as diferentes propostas apresentadas, como os presidenciáveis mostram em seus planos de governo os programas de redistribuição de renda.

\section{PROCEDIMENTOS METODOLÓGICOS}

O presente artigo trata do mapeamento dos planos de governo dos presidenciáveis nas eleições de 2018 com intuito de explicitar como são apresentados os programas de redistribuição de renda, procurando contribuir com o debate acerca das políticas sociais com foco na redistribuição de renda. Para tal fim, preliminarmente foi realizado um levantamento documental e uma revisão conceitual com o objetivo de reunir informações pertinentes acerca da inserção das políticas sociais na governança pública e dos programas de redistribuição de renda no Brasil, bem como os seus impactos na melhoria das condições de vida da população. Assim, uma vez realizado o levantamento teórico, no segundo momento, foi executada análise documental dos planos de governo dos treze candidatos à presidência da república.

A partir disso, esse estudo de caso, utilizou-se para atingir os objetivos propostos, o método qualitativo, que segundo Collis e Hussey (2005, p. 26) "[...] é mais subjetivo e envolve examinar e refletir as percepções para obter um entendimento de atividades sociais e humanas." Com o desenvolvimento dessa pesquisa qualitativa identifica-se e analisa-se as propostas referentes aos programas sociais de redistribuição de renda, por meio da análise de conteúdo das propostas apresentadas.

Sob a perspectiva de seus objetivos, o estudo apresenta um caráter descritivo. A pesquisa descritiva, na definição de Collis e Hussey (2005, p. 24) “[...] é a pesquisa que descreve o comportamento dos fenômenos". Com relação aos procedimentos, esse estudo pode ser classificado como uma pesquisa documental, já que na sua elaboração foram mapeados e analisados os planos de governo dos presidenciáveis registrados no TSE para as eleições de 2018.

Com isso, para alcançar os resultados propostos na pesquisa foi realizado um estudo documental nos programas de governos dos candidatos relacionados no quadro 1 a seguir. 


\section{Revista \\ UNEMAT de Contabilidade}

Quadro 1. Lista dos presidenciáveis eleições 2018:

\begin{tabular}{|c|c|c|}
\hline Candidato e Vice - (Partidos) & Número & Coligação \\
\hline $\begin{array}{l}\text { Alvaro Dias (Podemos) } \\
\text { Paulo Rabello de Castro (PSC) }\end{array}$ & 19 & Podemos, PSC, PRP e PTC. \\
\hline $\begin{array}{l}\text { Cabo Daciolo (Patriota) } \\
\text { Suelene Balduino Nascimento (Patriota) }\end{array}$ & 51 & Não. \\
\hline $\begin{array}{l}\text { Ciro Gomes (PDT) } \\
\text { Katia Abreu (PDT) }\end{array}$ & 12 & Não. \\
\hline $\begin{array}{l}\text { Eymael (DC) } \\
\text { Helvio Costa (DC) }\end{array}$ & 27 & Não. \\
\hline $\begin{array}{l}\text { Fernando Haddad (PT) } \\
\text { Manuela D'Ávila (PCdoB) }\end{array}$ & 13 & PT, PCDOB e PROS. \\
\hline $\begin{array}{l}\text { Geraldo Alckmin (PSDB) } \\
\text { Ana Amélia (PP) }\end{array}$ & 45 & $\begin{array}{l}\text { PSDB, PP, DEM, PR, Solidariedade, PRB, } \\
\text { PSD, PTB e PPS. }\end{array}$ \\
\hline $\begin{array}{l}\text { Guilherme Boulos (PSOL) } \\
\text { Sônia Guajajara (PSOL) }\end{array}$ & 50 & PSOL e PCB. \\
\hline $\begin{array}{l}\text { Henrique Meirelles (MDB) } \\
\text { Germano Rigotto (MDB) }\end{array}$ & 15 & MDB e PHS. \\
\hline $\begin{array}{l}\text { Jair Bolsonaro (PSL) } \\
\text { Hamilton Martins Mourão (PRTB) }\end{array}$ & 17 & PSL e PRTB \\
\hline $\begin{array}{l}\text { João Amoêdo (Novo) } \\
\text { Christian Lohbauer (Novo) }\end{array}$ & 30 & Não. \\
\hline $\begin{array}{l}\text { João Goulart filho (PPL) } \\
\text { Léo Alves (PPL) }\end{array}$ & 54 & Não. \\
\hline $\begin{array}{l}\text { Marina Silva ( Rede) } \\
\text { Eduardo Jorge (PV) }\end{array}$ & 18 & Rede e PV. \\
\hline $\begin{array}{l}\text { Vera (PSTU) } \\
\text { Hertz Dias (PSTU) }\end{array}$ & 16 & Não. \\
\hline
\end{tabular}

Fonte: Dados do TSE - Eleições 2018, elaborada pelos autores.

O quadro 1 apresenta a lista dos presidenciáveis em ordem alfabética, coloca seus números dispostos conforme registrados no Tribunal Superior Eleitoral (TSE) para exposição nas urnas eletrônicas, além disso aponta seus partidos e coligações. A partir do reconhecimento dos candidatos a coleta de dados foi através da busca dos respectivos planos de governo no site do TSE (TSE, 2018).

Com o mapeamento dos referidos planos de governo e a análise dos dados e informações pretende-se expor como os programas de redistribuição de renda são apresentados pelos candidatos. Após a coleta das informações e dos dados, passar-se-á a análise e interpretação deles. Lakatos (2010, p. 151) ressalta que "Uma vez manipulado os dados e obtidos os resultados, o passo seguinte é a análise e interpretação deles, constituindo-se ambas no núcleo central da pesquisa. " A análise dos dados coletados foi do tipo qualitativa, com análise de conteúdo nos programas de governo. Acerca da análise de conteúdo, Bardin (2016, p. 37) coloca que:

A análise de conteúdo é um conjunto de técnicas de análise das comunicações. Não se trata de um instrumento, mas de um leque de apetrechos; ou, com maior rigor, será um único instrumento, mas marcado por uma grande disparidade de formas e adaptável a um campo de aplicação muito vasto: as comunicações. 


\section{Revista \\ UNEMAT de Contabilidade}

Feito isso, a partir dos resultados alcançados, com a análise de conteúdo, foi traçado um ranking dos programas de governo de acordo com a apresentação dos programas de redistribuição de renda.

Baseado em Barros (2017), a fim de estabelecer um ranking dos planos de governo analisados e com isso identificar o grau de associação dos candidatos ao tema que trata dos programas de redistribuição de renda, foram estabelecidos pesos para os itens: ocorrência do tema, capítulo próprio para o tema e propostas específicas para o tema. Sendo valorado $(1,0)$ para sim e $(0,0)$ não, conforme ocorrência ou não dos referidos itens. A partir disso, para cada candidato, foi calculada a média ponderada dos três itens e estabelecido o escalonamento dos planos analisados. A relação dos referidos planos pesquisados está apresentada no quadro 2 a seguir.

Quadro 2- Planos de Governo 13 presidenciáveis eleições 2018.

\begin{tabular}{|c|c|c|c|}
\hline Candidato & Documento & $\mathrm{N}^{\circ}$ de páginas & Fonte \\
\hline Alvaro Dias & $\begin{array}{l}\text { Plano de metas } 19+1 \\
\text { Pela Refundação da } \\
\text { República }\end{array}$ & 15 & $\begin{array}{l}\text { http://divulgacandcontas.tse.jus.br/candidaturas/ } \\
\text { oficial/2018/BR/BR/2022802018/28000061846 } \\
\text { 2/proposta_1534304719669.pdf }\end{array}$ \\
\hline Cabo Daciolo & $\begin{array}{l}\text { Plano de nação para a } \\
\text { colônia brasileira. }\end{array}$ & 17 & $\begin{array}{l}\text { http://divulgacandcontas.tse.jus.br/candidaturas/ } \\
\text { oficial/2018/BR/BR/2022802018/28000060250 } \\
\text { 0/proposta_1533774159360.pdf }\end{array}$ \\
\hline Ciro Gomes & $\begin{array}{l}\text { Diretrizes para uma } \\
\text { estratégia nacional de } \\
\text { desenvolvimento para o } \\
\text { Brasil. }\end{array}$ & 62 & $\begin{array}{l}\text { http://divulgacandcontas.tse.jus.br/candidaturas/ } \\
\text { oficial/2018/BR/BR/2022802018/28000060558 } \\
\text { 9/proposta_1533938913830.pdf }\end{array}$ \\
\hline Eymael & $\begin{array}{l}\text { Diretrizes gerais de } \\
\text { governo para construir um } \\
\text { novo e melhor Brasil. }\end{array}$ & 09 & $\begin{array}{l}\text { http://divulgacandcontas.tse.jus.br/candidaturas/ } \\
\text { oficial/2018/BR/BR/2022802018/28000062408 } \\
\text { 5/proposta_1534450200223.pdf }\end{array}$ \\
\hline $\begin{array}{l}\text { Fernando } \\
\text { Haddad }\end{array}$ & O Brasil feliz de novo. & 61 & $\begin{array}{l}\text { http://divulgacandcontas.tse.jus.br/candidaturas/ } \\
\text { oficial/2018/BR/BR/2022802018/28000062980 } \\
\text { 8/proposta_1536702143353.pdf }\end{array}$ \\
\hline $\begin{array}{l}\text { Geraldo } \\
\text { Alckmin }\end{array}$ & $\begin{array}{l}\text { "Um futuro de } \\
\text { prosperidade está aberto a } \\
\text { todos os brasileiros" }\end{array}$ & 09 & $\begin{array}{l}\text { http://divulgacandcontas.tse.jus.br/candidaturas/ } \\
\text { oficial/2018/BR/BR/2022802018/28000060247 } \\
\text { 7/proposta_1533849607885.pdf }\end{array}$ \\
\hline $\begin{array}{l}\text { Guilherme } \\
\text { Boulos }\end{array}$ & $\begin{array}{l}\text { Vamos sem medo de } \\
\text { mudar o Brasil. }\end{array}$ & 228 & $\begin{array}{l}\text { http://divulgacandcontas.tse.jus.br/candidaturas/ } \\
\text { oficial/2018/BR/BR/2022802018/28000060101 } \\
\text { 6/proposta_1533565462424.pdf }\end{array}$ \\
\hline $\begin{array}{l}\text { Henrique } \\
\text { Meirelles }\end{array}$ & Pacto pela confiança! & 21 & $\begin{array}{l}\text { http://divulgacandcontas.tse.jus.br/candidaturas/ } \\
\text { oficial/2018/BR/BR/2022802018/28000062228 } \\
\text { 1/proposta_1534354939646.pdf }\end{array}$ \\
\hline Jair Bolsonaro & $\begin{array}{l}\text { O caminho da } \\
\text { prosperidade. }\end{array}$ & 81 & $\begin{array}{l}\text { http://divulgacandcontas.tse.jus.br/candidaturas/ } \\
\text { oficial/2018/BR/BR/2022802018/28000061451 } \\
\text { 7/proposta_1534284632231.pdf }\end{array}$ \\
\hline João Amoêdo & $\begin{array}{l}\text { Mais oportunidades menos } \\
\text { privilégios. }\end{array}$ & 23 & $\begin{array}{l}\text { http://divulgacandcontas.tse.jus.br/candidaturas/ } \\
\text { oficial/2018/BR/BR/2022802018/28000060764 } \\
\text { 0/proposta_1534522080782.pdf }\end{array}$ \\
\hline $\begin{array}{l}\text { João Goulart } \\
\text { filho }\end{array}$ & $\begin{array}{l}\text { Distribuir a renda, superar } \\
\text { a crise e desenvolver o } \\
\text { Brasil. }\end{array}$ & 14 & $\begin{array}{l}\text { http://divulgacandcontas.tse.jus.br/candidaturas/ } \\
\text { oficial/2018/BR/BR/2022802018/28000062408 } \\
\text { 2/proposta_1534349279487.pdf }\end{array}$ \\
\hline Marina Silva & $\begin{array}{l}\text { Brasil justo, ético, } \\
\text { próspero e sustentável. }\end{array}$ & 24 & $\begin{array}{l}\text { http://divulgacandcontas.tse.jus.br/candidaturas/ } \\
\text { oficial/2018/BR/BR/2022802018/28000062217 }\end{array}$ \\
\hline
\end{tabular}




\section{Revista \\ UNEMAT de Contabilidade}

\begin{tabular}{|l|l|l|l|}
\hline & & & 1/proposta_1535040841979.pdf \\
\hline Vera & $\begin{array}{l}\text { 16 pontos de um programa } \\
\text { socialista para o Brasil } \\
\text { contra a crise capitalista. }\end{array}$ & \multirow{2}{*}{05} & $\begin{array}{l}\text { http://divulgacandcontas.tse.jus.br/candidaturas/ } \\
\text { oficial/2018/BR/BR/2022802018/28000060117 } \\
\text { 3/proposta_1533576953009.pdf }\end{array}$ \\
\hline
\end{tabular}

Fonte: Dados do TSE- Eleições 2018, elaborada pelos autores.

O quadro 2 apresenta as fontes de pesquisa das propostas dos 13 candidatos à presidente do Brasil nas eleições de 2018 que foram retiradas, no dia 02 de outubro de 2018, do site do TSE. Uma vez apresentado os planos de governo dos presidenciáveis realizou-se a análise de conteúdo deles conforme os resultados descritos no item a seguir.

\section{ANÁLISE E DISCUSSÃo DOS RESULTADOS}

\subsection{Ranking dos programas de governo de acordo com a apresentação dos programas de redistribuição de renda.}

O tema que trata acerca dos programas de redistribuição de renda foi explorado com base nos planos de governo protocolados na Justiça Eleitoral para as eleições presidenciais de 2018. A partir desse levantamento a tabela 1 apresenta o rankeamento a partir da análise dos planos de governo dos presidenciáveis nas eleições de 2018 no que se refere aos programas de redistribuição de renda.

Tabela 1 - Planos de Governo 13 presidenciáveis eleições 2018.

\begin{tabular}{|l|c|c|c|c|c|c|c|}
\hline Candidato & \multicolumn{2}{l}{ Ocorrência/peso } & \multicolumn{2}{l}{ Capítulo próprio/peso } & \multicolumn{2}{l}{ Propostas/peso } \\
\hline Alvaro Dias & Não & 0,00 & Não & 0,00 & Não & 0,00 & 0,00 \\
\hline Cabo Daciolo & Sim & 1,00 & Não & 0,00 & Não & 0,00 & 0,33 \\
\hline Ciro Gomes & Sim & 1,00 & Sim & 1,00 & Sim & 1,00 & 1,00 \\
\hline Eymael & Não & 0,00 & Não & 0,00 & Não & 0,00 & 0,00 \\
\hline Fernando Haddad & Sim & 1,00 & Não & 0,00 & Sim & 1,00 & 0,66 \\
\hline Geraldo Alckmin & Sim & 1,00 & Não & 0,00 & Sim & 1,00 & 0,66 \\
\hline Guilherme Boulos & Sim & 1,00 & Sim & 1,00 & Sim & 1,00 & 1,00 \\
\hline Henrique Meirelles & Sim & 1,00 & Não & 0,00 & Não & 0,00 & 0,33 \\
\hline Jair Bolsonaro & Sim & 1,00 & Não & 0,00 & Sim & 1,00 & 0,66 \\
\hline João Amoêdo & Sim & 1,00 & Sim & 1,00 & Sim & 1,00 & 1,00 \\
\hline João Goulart filho & Sim & 1,00 & Não & 0,00 & Não & 0,00 & 0,33 \\
\hline Marina Silva & Sim & 1,00 & Sim & 1,00 & Sim & 1,00 & 1,00 \\
\hline Vera & Não & 0,00 & Não & 0,00 & Não & 0,00 & 0,00 \\
\hline
\end{tabular}

Fonte: Dados do TSE- Eleições 2018, elaborada pelos autores.

Pelo exposto na tabela 1 verifica-se que não foi possível identificar a presença de programas de redistribuição de renda em todos os planos de governo analisados, além disso nem todos apresentam capítulo próprio e/ou propostas. Com isso, a partir do ranking estabelecido através dos registros do tema pesquisado será apresentado no item a seguir os resultados encontrados na análise de conteúdo dos planos de governo. 


\section{Revista

\subsection{Análise de conteúdo dos planos de governo no que se refere a apresentação dos programas sociais e de redistribuição de renda.}

Conforme apresentado na tabela 1 foram analisadas a ocorrência, o desenvolvimento em capítulo próprio e a presença de propostas acerca dos programas sociais e de redistribuição de renda nos planos de governo dos candidatos à presidência: Alvaro Dias (Podemos), Cabo Daciolo (Patriota), Ciro Gomes (PDT), Eymael (PSDC), Fernando Haddad (PT), Geraldo Alckmin (PSDB), Guilherme Boulos (PSol), Henrique Meirelles (MDB), Jair Bolsonaro (PSL), João Amoêdo (Novo), João Goulart Filho (PPL), Marina Silva (Rede) e Vera (PSTU).

Nos planos de governo dos(as) candidatos(as) Alvaro Dias, Eymael e Vera não houve nenhum tipo referência à programas sociais e de redistribuição de renda. Nota-se nesses casos que os candidatos não fizeram referência, não apresentaram capítulo próprio nem propostas para o tema em seus planos de governo. Nos programas de governo dos candidatos Cabo Daciolo, Henrique Meirelles e João Goulart Filho foi possível verificar a ocorrência do tema, no entanto não havia um capítulo próprio nem propostas para os programas sociais e de redistribuição de renda.

Para os candidatos Fernando Haddad, Geraldo Alckmin e Jair Bolsonaro foi verificada a ocorrência do tema, bem como propostas para o desenvolvimento dos os programas sociais de redistribuição de renda, conforme pode ser verificado no quadro 3.

Quadro 3 - Análise de conteúdo das propostas de redistribuição de renda nos Planos de Governo dos Presidenciáveis Fernando Haddad, Geraldo Alckmin e Jair Bolsonaro

Fonte: Elaborada pelos autores.

\begin{tabular}{|c|c|c|}
\hline Candidato & Propostas & Palavras chaves \\
\hline Fernando Haddad & $\begin{array}{l}\text { "Reforçar os investimentos no programa Bolsa Família, incluindo } \\
\text { aqueles que voltaram à pobreza com o golpe;" } \\
\text { "O governo Haddad vai incorporar as famílias em condição de pobreza } \\
\text { sem acesso ao Bolsa família e promoverá a universalização da } \\
\text { segurança de renda e ampliação de cobertura quanto a fatores de } \\
\text { insegurança e desproteção social, especialmente inclusão produtiva." } \\
\text { "O governo federal vai ampliar o uso do Cadastro Único como fonte } \\
\text { de diagnóstico para a implementação de políticas sociais, conforme as } \\
\text { demandas específicas de cada segmento, tendo como norte o combate } \\
\text { às desigualdades sociais, de gênero, étnico-racial e territorial. Além } \\
\text { realizar a efetiva integração } 31 \text { dos sistemas públicos e qualificação } \\
\text { dos serviços prestados, o governo federal avançará na implementação } \\
\text { da Lei n. } 10.835 \text {, de } 2004 \text {, que institui a renda básica de cidadania." }\end{array}$ & $\begin{array}{l}\text { Reforçar } \\
\text { investimentos; } \\
\text { Acesso; } \\
\text { Bolsa Família; } \\
\text { Universalização da } \\
\text { segurança de renda; } \\
\text { Ampliação } \\
\text { cobertura; } \\
\text { Renda básica de } \\
\text { cidadania. }\end{array}$ \\
\hline Geraldo Alckmin & $\begin{array}{l}\text { "Vamos incrementar o programa Bolsa Família, aumentando os } \\
\text { benefícios para os mais necessitados" }\end{array}$ & $\begin{array}{l}\text { Incrementar; } \\
\text { Bolsa família; } \\
\text { Aumentando os } \\
\text { benefícios. }\end{array}$ \\
\hline Jair Bolsonaro & $\begin{array}{l}\text { "Acima do valor do bolsa família pretendemos instituir uma renda } \\
\text { mínima para todas as famílias brasileiras. Propomos a modernização e } \\
\text { aprimoramento do programa Bolsa Família e do Abono Salarial, com } \\
\text { vantagens para os beneficiários." }\end{array}$ & $\begin{array}{l}\text { Bolsa Família; } \\
\text { Renda mínima; } \\
\text { Abono salarial. }\end{array}$ \\
\hline
\end{tabular}

De acordo com os dados do quadro 3. O candidato Fernando Haddad apresenta três principais propostas no que se refere aos programas de redistribuição de renda. $\mathrm{O}$ cadastro Único 


\section{Revista \\ UNEMAT de Contabilidade}

citado pelo candidato diz respeito, segundo o Ministério de Desenvolvimento Social (MDS), a um instrumento de identificação de famílias de baixa renda, sua residência, quem compõem o grupo familiar, escolaridade, situação trabalho e outras informações importantes para que o governo pense em medidas ou ações estratégicas voltadas a esse público alvo. É através do cadastro único que essa população tem acesso ao programa bolsa família e ao benefício de prestação continuada, além de outros programas com menor cobertura, como por exemplo, o ID jovem. Assim, Haddad reafirma a importância da ampliação desse cadastro, universalização da segurança de renda e reforço no financiamento público dessas ações.

No mesmo sentido Geraldo Alckim afirma como proposta o incremento do programa Bolsa Família e dos benefícios dele decorrentes, muito embora, não explane a operacionalidade dessa expansão. Jair Bolsonaro retoma a discussão da renda mínima para as famílias em situação de pobreza. O candidato também propôs o aprimoramento do programa Bolsa Família e do Abono Salarial. Portanto, os três candidatos supracitados abordam o tema da transferência de renda e apresentam ao menos uma proposta, no entanto, não possuem capítulo próprio no programa de governo no que se refere ao tema.

Nos planos de governo dos candidatos Ciro Gomes, Guilherme Boulos, João Amoêdo e Marina Silva foram os que melhor contemplaram o tema de redistribuição de renda. Os seus planos de governo comtemplam a ocorrência do tema em capítulo próprio e com o desenvolvimento de propostas. O detalhamento da política de redistribuição de renda apresentada por esses candidatos é colocado no quadro 4.

Quadro 4 - Análise de conteúdo do capítulo próprio e das propostas de redistribuição de renda nos dos Planos de Governo dos Ciro Gomes, Guilherme Boulos, João Amoêdo e Marina Silva

\begin{tabular}{|c|c|c|c|}
\hline Candidato & Capítulo próprio & Propostas & Palavras chaves \\
\hline Ciro Gomes & $\begin{array}{l}\text { 8. Criar, manter e } \\
\text { ampliar os programas } \\
\text { sociais." }\end{array}$ & $\begin{array}{l}\text { "Todos os programas sociais que existem } \\
\text { atualmente e estão obtendo bons resultados } \\
\text { serão mantidos e ampliados na medida das } \\
\text { necessidades, como por exemplo o Bolsa } \\
\text { Família, o Benefício da Prestação Continuada, o } \\
\text { ProUni, o sistema de cotas nas universidades e o } \\
\text { Farmácia Popular, dentre outros. Mas } \\
\text { precisamos avançar e vamos propor outros } \\
\text { programas, em adição aos já existentes." }\end{array}$ & $\begin{array}{l}\text { Programas sociais; } \\
\text { Mantidos e ampliados; } \\
\text { Bolsa família; } \\
\text { Benefício da Prestação } \\
\text { Continuada; } \\
\text { Propor outros } \\
\text { programas. }\end{array}$ \\
\hline $\begin{array}{l}\text { Guilherme } \\
\text { Boulos }\end{array}$ & $\begin{array}{l}\text { " } 4 . \text { Emprego, renda e } \\
\text { moradia." }\end{array}$ & $\begin{array}{l}\text { "Aumentar o valor do Programa Bolsa Família } \\
\text { para transformá-lo em uma Renda Básica de } \\
\text { Cidadania Universal, como política pública e } \\
\text { direito social, [...]." } \\
\text { "Estabelecer um orçamento da Seguridade } \\
\text { Social com os recursos canalizados para um } \\
\text { fundo específico que servirá para o pagamento } \\
\text { de benefícios, serviços, ações e programas no } \\
\text { âmbito das políticas que integram a Seguridade } \\
\text { Social [...]. Ampliar significativamente a } \\
\text { transferência de recursos para os serviços sócio } \\
\text { assistenciais, considerando que hoje quase todo } \\
\text { o orçamento da Assistência Social se dirige para } \\
\text { a transferência de renda, e que há uma }\end{array}$ & $\begin{array}{l}\text { Aumentar o valor; } \\
\text { Bolsa Família; } \\
\text { Renda Básica; } \\
\text { Pagamento de } \\
\text { benefícios; } \\
\text { Ampliar; } \\
\text { Transferência de } \\
\text { recursos; } \\
\text { Transferência de renda. }\end{array}$ \\
\hline
\end{tabular}




\section{Revista \\ UNEMAT de Contabilidade}

\begin{tabular}{|c|c|c|c|}
\hline & & $\begin{array}{l}\text { concentração da carga tributária na União que } \\
\text { dificulta o co-financiamento na esfera local." }\end{array}$ & \\
\hline $\begin{array}{l}\text { João } \\
\text { Amoêdo }\end{array}$ & $\begin{array}{l}\text { "Proteção social como } \\
\text { um caminho para a } \\
\text { cidadania plena e fim } \\
\text { da pobreza." }\end{array}$ & $\begin{array}{l}\text { "O Brasil ainda precisa de um eficiente } \\
\text { programa de proteção social para atender aos } \\
\text { que mais necessitam e funcionar como uma } \\
\text { ponte para a cidadania plena. O Bolsa Família é } \\
\text { um exemplo de programa bem-sucedido e deve } \\
\text { ser mantido e aperfeiçoado." }\end{array}$ & $\begin{array}{l}\text { Bolsa Família; } \\
\text { Programa bem- } \\
\text { sucedido; } \\
\text { Mantido e } \\
\text { aperfeiçoado. }\end{array}$ \\
\hline $\begin{array}{l}\text { Marina } \\
\text { Silva }\end{array}$ & $\begin{array}{l}\text { "Garantia dos direitos } \\
\text { Sociais e inclusão } \\
\text { Produtiva." }\end{array}$ & $\begin{array}{l}\text { "Programas de transferência de renda, como o } \\
\text { Bolsa Família, são fundamentais para atender a } \\
\text { situação emergencial das pessoas que se veem } \\
\text { impossibilitadas de prover suas necessidades } \\
\text { básicas. Estes programas devem ser preservados } \\
\text { e reconhecidos como direitos assegurados por } \\
\text { lei e devem ser associados às condições para a } \\
\text { inclusão produtiva e garantia do direito a } \\
\text { oportunidades. Estudaremos, ainda, as } \\
\text { possibilidades da implantação de programa de } \\
\text { renda mínima Universal. [...]" }\end{array}$ & $\begin{array}{l}\text { Programas de } \\
\text { transferência de renda; } \\
\text { Bolsa família; } \\
\text { Ser preservados; } \\
\text { Programa de renda } \\
\text { mínima Universal. }\end{array}$ \\
\hline
\end{tabular}

Fonte: Elaborada pelos autores.

O quadro 4 aponta para os capítulos próprios referentes a programas de transferência ou redistribuição de renda dos candidatos Ciro Gomes, Guilherme Boulos, João Amoedo e Marina Silva. Ciro Gomes tem como título do capítulo "Criar, manter e ampliar os programas sociais" o que resume bem as propostas do candidato. Ciro Gomes defende como proposta a continuidade dos programas Bolsa Família, Benefício de Prestação Continuada e demais programas de cunho social, a ampliação na cobertura desses e a construção de novos programas. $O$ candidato Guilherme Boulos em seu capítulo "Emprego, renda e moradia" defende o aumento do valor monetário pago pelo Programa Bolsa Família, associando a renda básica de cidadania, assim como, um financiamento próprio a seguridade social que contemple os recursos dos programas de transferência de renda, ampliando o financiamento da política de Assistência Social. Também defende a promoção de parcerias entre União e municípios no que se refere ao co-financimento das políticas de redistribuição de renda.

O candidato João Amoedo tem como título do capítulo específico sobre a temática "Proteção social como um caminho para a cidadania plena e fim da pobreza" defende a ampliação e continuidade do Programa Bolsa Família. A candidata Marina Silva no capítulo "Garantia dos direitos sociais e inclusão produtiva" reforça a importância dos programas de redistribuição de renda no atendimento emergencial a pessoas em situação de vulnerabilidade decorrente da pobreza. Afirma, como proposta o estudo para verificar a viabilidade de implantação de um programa de renda mínima universal.

Todos os candidatos que citaram, apresentaram propostas ou capítulo próprio sobre os programas de redistribuição ou transferência de renda afirmam defender a continuidade e a ampliação do Programa Bolsa Família. Essa concepção é muito importante pois, a política social tem sido cada vez mais reduzida, voltadas a situações extremas com alto grau de seletividade e focalização (RACHELIS, 2013). Assim, inclui apenas uma parte da população que se vê carente de iniciativas governamentais, os deixando a margem da proteção social do Estado. 


\section{Revista \\ UNEMAT de \\ Contabilidade}

\section{CONSIDERAÇÕES FINAIS}

É reconhecida a importância das eleições para a definição e o estabelecimento das políticas públicas que serão prioridade nas agendas dos governos que podem vir a ser eleitos. Para tanto, destaca-se a necessidade de se ter um contato com os planos de governo dos candidatos à presidência da república e fazer um comparativo das propostas para a fim de que seja possível visualizar quais atendem melhor aos anseios da coletividade.

No que diz respeito especificamente aos programas de redistribuição de renda aponta-se a relevância desses para a proteção social de famílias em vulnerabilidade, bem como, a sua importância estratégica no desenvolvimento do país. Tendo em vista a profunda desigualdade social vivenciadas pela população brasileira é preocupante o fato de que nem todos os treze presidenciáveis tenham contemplado em seus planos de governo programas de redistribuição de renda. Além disso, chama a atenção que muito embora três deles tenham citado, não apresentaram propostas. Sendo que dos treze candidatos, apenas sete contemplaram propostas de redistribuição de renda sólidas.

Pela análise de conteúdo dos planos de governo dos presidenciáveis nas eleições de 2018, a partir do comparativo no que concerne aos programas sociais, com ênfase nos programas de redistribuição de renda, fica claro que todos os candidatos que apresentaram propostas referentes aos programas de redistribuição de renda concordam ao ressaltar a necessidade de continuidade e ampliação da cobertura do programa. Quatro dos candidatos citaram o programa de renda mínima que mesmo tendo sido normatizado em 2004 ainda não foi efetivado, como um passo importante para a garantia dos direitos da população em situação de pobreza ou miséria. Porém, apenas um candidato discutiu o financiamento dessas ações, demonstrando de que forma pretende executar ampliação dos programas de redistribuição de renda.

Cabe destacar que para além das propostas registradas nos planos de governo, a população deve acompanhar as ações após a posse do candidato eleito a fim de fiscalizar se a agenda governamental corresponde ao plano referido. Nesse sentido, os mecanismos de controle social perpassam as ferramentas de transparência online disponíveis pelo governo, assim como, instâncias presencias como os conselhos municipais, estaduais e nacionais de direitos e políticas públicas. A participação social, portanto, não se resume a escolha de um candidato no pleito presidencial.

O estudo teve como limitação o acompanhamento das ações do candidato eleito e se essas correspondem ao plano de governo. Tendo em vista que não há uma sanção legal no não cumprimento desse, sugere-se estudos que comparem as propostas contidas no plano de governo as ações e medidas governamentais dos candidatos eleitos.

\section{REFERÊNCIAS}

ARAÚJO, V.; FLORES, P. Redistribuição de renda, pobreza e desigualdade territorial no Brasil. Revista Sociologia e Política, v. 25, n. 63, p. 159-182, set. 2017.

BARDIN, L. Análise de conteúdo. São Paulo, SP: Edições 70, 2016. 


\section{Revista \\ UNEMAT de \\ Contabilidade}

BANCO MUNDIAL, Como reduzir a pobreza: uma nova lição do Brasil para o mundo? Disponível em: http://www.worldbank.org/pt/news/feature/2014/03/22/mundo-sin-pobrezaleccion-brasil-mundo-bolsa-familia Acesso em: 15 de nov. de 2018

BARROS, A. T. de. Política partidária e meio ambiente: a adesão dos partidos políticos brasileiros à agenda verde. Opinião Pública, vol.21, n.3, pp.693-733, 2015.

BARROS, A. T. de A governança ambiental nos planos de governo dos presidenciáveis nas eleições de 2014. Revista Brasileira de Ciência Política, nº 23. Brasília, maio - agosto, pp 181216, 2017.

BARROS, L. F. do R.; ELLIOT, L. G. Meta-Avaliação do Relatório de Avaliação da Execução de Programas de Governo $n^{\circ}$ 8: programa saúde da família. Revista Meta: Avaliação, Rio de Janeiro, Edição Especial nº 2, p. 197-224, 2018.

BEHRING, E. R.; BOSCHETTI, I. B. Política Social: fundamentos e História. São Paulo: Cortez, 2007.

BEHRING, E. R. Fundamentos de Política Social. Disponível em: http://www.fnepas.org.br/pdf/servico_social_saude/texto1-1.pdf Acesso em: 17 de nov. de 2018.

BRASIL, LEI No 9.504, DE 30 DE SETEMBRO DE 1997, Estabelece normas para as eleições. Disponível em: http://www.planalto.gov.br/ccivil_03/leis/L9504compilado.htm Acesso em: 19 set. 2018.

BRASIL. Ministério de Desenvolvimento Social. Cadastro Único: o que é, para que serve. Disponível em: http://mds.gov.br/assuntos/cadastro-unico/o-que-e-e-para-que-serve Acesso em: 06 de dez. de 2018.

COLliS, J.; E HUSSEY, R. Pesquisa em Administração - Um guia Prático para alunos de Graduação e Pós-graduação. Porto Alegre: Bookman, 2. Ed., 2005.

DALLARI, D. de A. O que é participação política. $16^{\circ}$ Ed., Editora e Livraria Brasiliense, São Paulo-SP, 2010.

FERLA, A. A.; Pinto, H.A.; Possa, L.B.; Trepte, R.F.; Ceccim, R.B. Ideias, imagens e crenças na produção de políticas públicas: o caso do Programa Mais Médicos. Interface - Comunicação, Saúde, Educação, v. 21, suppl.1, pp.1129-1141, 2017.

JACOB, C.R.; HEES, D.R.; WANIEZ, P; BRUSTLEIN, V. As eleições presidenciais no Brasil pós-ditadura militar: continuidade e mudança na geografia eleitoral. Revista Alceu, Rio de Janeiro 2000.

KINZO, M. D'A. G. A DEMOCRATIZAÇÃO BRASILEIRA: um balanço do processo político desde a transição. São Paulo Perspec, vol.15 no.4 São Paulo, Oct./Dec., 2001.

LAKATOS, E. M.; MARCONI, M. de A. Fundamentos de metodologia científica. São Paulo, SP: Atlas, 2010. 


\section{Revista \\ UNEMAT de \\ Contabilidade}

MADEIRA, R.; VIEIRA, S.; TAROUCO, G. Agendas, preferências, competição: PT e PSDB em disputas presidenciais. Caderno CRH, Salvador, v. 30, n. 80, p. 257-273, Maio/Ago. 2017.

MARINHO, E. ; LINHARES, F.; CAMPELO, G. Os programas de transferência de renda do governo impactam a pobreza no Brasil? Revista Brasileira de Economia, v.65, no. 3, Rio de Janeiro, July/Sept., 2011.

MILANI, C. R. S. O princípio da participação social na gestão de políticas públicas locais: uma análise de experiências latino-americanas e europeias. Revista de Administração Pública, Rio de Janeiro, v. 42, n. 3, pp. 551-79, maio/Jun. 2008.

PIANA, M. C. A construção do perfil do assistente social no cenário educacional. São Paulo: Editora UNESP; São Paulo: Cultura Acadêmica, 2009. 233 p.

PIANA, M. C. As políticas sociais no contexto brasileiro: natureza e desenvolvimento. SciELO Books. Disponível em: http://books.scielo.org/id/vwc8g/pdf/piana-978857983038902.pdf Acesso em: 16 de nov. de 2018.

RAICHELIS, R. Proteção Social e trabalho do assistente social: tendências e disputas na conjuntura de crise econômica mundial. Serv. Soc. Soc., São Paulo, n. 116, 2013.

SILVA, M. O. da S e. O Bolsa Família: problematizando questões centrais na política de transferência de renda no Brasil. Revista Ciência \& Saúde Coletiva, v. 12, n. 6, p.1429-1439, 2007.

SILVA, M. O. da S.; YASBEK, M. C.; GIOVANNI, G. di. A Política Social Brasileira no Século XXI: a prevalência dos programas de transferência de renda. São Paulo: Cortez, 2004

SOARES, F. V.; SOARES, S.; MEDEIROS, M.; OSÓRIO, R. G. Programas de Transferência de Renda no Brasil: impactos sobre a desigualdade. Instituto de Pesquisa Econômica Aplicada (Ipea), Brasília, outubro de 2006. Disponível em: http://www.ipea.gov.br/portal/index.php?option=com_content\&view=article\&id=4374 Acesso em: 17 de nov. de 2018.

SUPLICY, E. M. Renda de cidadania: a saída é pela porta. 2a . ed. São Paulo: Cortez, 2002

VAITSMAN, J.; ANDRADE, G. R. B. de; FARIAS, L. O. Proteção social no Brasil: o que mudou na assistência social após a Constituição de 1988. Revista Ciência \& Saúde Coletiva, v. 14, n. 3, 2009.

TSE. Propostas de governo dos candidatos ao cargo de Presidente da República. Tribunal Superior Eleitoral, 2018. Disponível em: http: //www.tse.jus.br/eleicoes/eleicoes2018/propostas-de-candidatos. Acesso em: 20 de out. de 2018.

YASBEK, M. C. O programa fome zero no contexto das políticas sociais brasileiras. São Paulo em Perspectiva, vol. 18, no.2, São Paulo, Apr./June, 2004. 